Romanée Zander

Der Stand der Dinge

Edition Moderne Postmoderne 
Meinen Eltern

Romanée Zander (Dr. phil.), geb. 1983, lebt in London und arbeitet für eine internationale Kinderhilfsorganisation. Nach seinem Studium der Philosophie, Psychologie und Kunstgeschichte promovierte er in Philosophie und war 2013 Visiting Scholar und Gastwissenschaftler an der Columbia University in New York. 
ROMANÉE ZANDER

\section{Der Stand der Dinge}

Über das Zusammenspiel von Sprache, Wahrnehmung

und ästhetischer Bedeutung 
Dissertation Johann Wolfgang Goethe-Universität Frankfurt am Main, Fachbereich o8 Philosophie und Geschichtswissenschaften, o6. Februar 2019.

Titel der Dissertation: Der Stand der Dinge. Zum Spiel der Erkenntnis

Sigelziffer D.30

\section{Bibliografische Information der Deutschen Nationalbibliothek}

Die Deutsche Nationalbibliothek verzeichnet diese Publikation in der Deutschen Nationalbibliografie; detaillierte bibliografische Daten sind im Internet über http://dnb.d-nb.de abrufbar.

\section{(C) 2019 transcript Verlag, Bielefeld}

Alle Rechte vorbehalten. Die Verwertung der Texte und Bilder ist ohne Zustimmung des Verlages urheberrechtswidrig und strafbar. Das gilt auch für Vervielfältigungen, Übersetzungen, Mikroverfilmungen und für die Verarbeitung mit elektronischen Systemen.

Umschlaggestaltung: Kordula Röckenhaus, Bielefeld Druck: Majuskel Medienproduktion GmbH, Wetzlar Print-ISBN 978-3-8376-4995-6 PDF-ISBN 978-3-8394-4995-0 https://doi.org/10.14361/9783839449950

Gedruckt auf alterungsbeständigem Papier mit chlorfrei gebleichtem Zellstoff. Besuchen Sie uns im Internet: https://www.transcript-verlag.de Unsere aktuelle Vorschau finden Sie unter www.transcript-verlag.de/vorschau-download 